\title{
LA INVESTIGACIÓ SOCIOINTERACCIONAL DE L'EMPRESA APLICADA A LA FORMACIÓ COMUNICATIVA DELS EMPLEATS ${ }^{1}$
}

\author{
Gabriela Prego Vázquez
}

Universitat de Santiago de Compostel la

\section{INTRODUCCIÓ}

L'estudi de la comunicació en contextos professionals ha estat una conquesta tardana dels estudis lingüístics. Mentre que la psicologia social s'ha ocupat tradicionalment d'aquest camp, en l'àmbit de la lingüística no es van fer treballs sistemàtics sobre la parla en les empreses fins a la dècada de 1990. Aquests tipus d'investigacions s'han desenvolupat fonamentalment en el marc de l'anàlisi del discurs. Els estudis d'analistes de la conversa (Bargiela-Chiappini i Harris 1997; Boden i Zimmerman 1991; Drew i Heritage 1992; Gunnarson, et al. 1997; Sarangi i Roberts 1999), sociolingüistes interaccionals (Gumperz 1982a; 1982b; Gumperz et al. 1979; Pan, Wong i Scollon 2002) o analistes crítics del discurs (Martín Rojo i Gómez Esteban 2002; Wodak 1996) no només revelen les característiques de les pràctiques comunicatives de les persones que treballen juntes $\mathrm{i}$ que interactuen sistemàticament $\mathrm{amb}$ el públic; també aporten pautes per a la planificació i gestió comunicatives. Concretament, en aquest article abordarem una de les tasques associades a la planificació comunicativa de l'empresa: la formació dels professionals. Mostrarem com els estudis sociointeraccionals poden contribuir al disseny d'una formació adequada al context particular de cada empresa.

\footnotetext{
1 El finançament d'aquesta investigació prové dels projectes «Comunicación en la Empresa y en las Instituciones: Análisis del Discurso y Retórica» (del Ministerio de Educación y Ciencia, amb referència HUM2007-61936FILO) i «Logopedia y Lingüística de Corpus. Exploración del Habla Infantil y del Afásico» (del Ministerio de Educación y Ciencia, amb referència HUM2007-66074-C02-01).
}

2. DE LA COMPETÈNCIA COMUNICATIVA A LA COMPETĖNCIA METACOMUNICATIVA PROFESSIONAL

Gumperz i Hymes (1972, pàg. vii) defineixen la competència comunicativa com 'allò que un parlant necessita saber per comunicarse de manera eficaç en contextos culturalment significants'. Així, la competència comunicativa inclou, a més de la gramàtica, les habilitats que els parlants posseeixen per mobilitzar els recursos lingüístics de manera adequada en relació amb els factors contextuals i el coneixement de convencions i expectatives que els permet participar cooperativament en l'intercanvi comunicatiu $\mathrm{i}$ interpretar les intencions dels interlocutors.

Des de la infantesa, i fruit de la participació en diferents tipus d'activitats socials, adquirim pautes de comportament verbal: quan cal parlar, com ens hem de dirigir a individus amb diferents estatus, com cal preguntar, com es pot convèncer en funció del participant o el context, etc. Posseïm, a més una gramàtica, habilitats comunicatives i certa consciència de com funcionen. Denominem aquesta consciència lingüística i comunicativa competència metacomunicativa.

La competència metacomunicativa ens permet valorar les coordenades contextuals a l'hora de fer una elecció lingüística o de planificar estratègies comunicatives. Des de molt petits sabem com convèncer la mare $o$ el pare, no parlem de la mateixa manera amb coneguts que amb desconeguts, i planifiquem les intervencions quan volem convèncer, rebatre o informar d'assumptes delicats a algú. En aquest sentit, doncs, la competència metacomunicativa és crucial a l'hora 
d'esdevenir bons comunicadors i és una qualitat important que han de posseir els professionals de les empreses, per a qui el llenguatge és un instrument de treball.

En aquest sentit, considerem rellevant que els professionals rendibilitzin les reflexions sobre el procés comunicatiu. Es tracta de reforçar la competència metacomunicativa per aconseguir el que denominarem competència metacomunicativa professional. I, com veurem al llarg d'aquest article, els recursos procedents de l'anàlisi del discurs són crucials per a aquesta tasca.

3. Per QuÈ LA inVestigació SOCIOINTERACCIONAL DE L'EMPRESA PERMET UNA FORMACIÓ EFICAÇ DELS EMPLEATS?

Els estudis sociointeraccionals constitueixen un marc multidisciplinari ampli que es nodreix dels recursos d'anàlisis procedents de la pragmàtica, l'etnografia de la comunicació, l'anàlisi de la conversa, la sociolingüística interaccional i l'anàlisi crítica del discurs. L'objectiu d'aquestes investigacions és estudiar l'ús del llenguatge en el context comunicatiu i sociocultural. Aquest enfocament metodològic aplicat tant a l'estudi de la conversa espontània com a la parla d'empreses i institucions revela com funciona el procés comunicatiu. L'anàlisi de pràctiques discursives reals evidencia que l'ús del llenguatge consisteix en una elecció contínua, de manera conscient o inconscient, dels diferents recursos lingüístics del repertori.

El pragmatòleg Jeff Verschueren (1999) considera tres característiques del llenguatge humà implicades en aquesta elecció contínua: variabilitat, negociabilitat i adaptabilitat. Així, en el moment de transmetre un missatge, una llengua sempre ens ofereix diferents maneres d'expressar-lo. La variabilitat és 'la propietat del llenguatge que defineix la gamma de possibilitats entre les quals es poden fer les eleccions'. Amb tot, aquestes eleccions no es fan mecànicament sinó a partir de funcions i estratègies de caràcter flexible que tenen en compte factors contextuals com l'interlocutor o els fins comunicatius. La negociabilitat és 'la propietat que permet aquesta flexibilitat'. I, finalment, l'adaptabilitat està vinculada a les possibles modificacions que es fan de les estratègies per adequar-se a les metes i necessitats comunicatives dels participants.

Per tant, les mesures pràctiques orientades a la formació dels professionals de les empreses no poden procedir de rutines fixes. A més, tot i que són abundants els manuals que ens ofereixen receptes màgiques per ser bons comunicadors, hem de dubtar de tots els que no responguin a la variabilitat, flexibilitat i recontextualització i reinterpretació constants del procés comunicatiu. Així mateix, cal planificar quins recursos lingüístics cal mobilitzar en funció de:

a) El propòsit general de cada empresa i el propòsit particular de cadascuna de les activitats comunicatives.

b) Els tipus de client.

c) Els tipus de contextos.

d) Els patrons comunicatius més recurrents en l'empresa.

En aquest sentit, considerem necessari fer una anàlisi sociodiscursiva de les pràctiques lingüístiques $i$ aplicar els resultats a la planificació comunicativa per mitjà de la formació dels empleats. Es tracta d'un treball d'investigació-acció que consta de diverses fases. Així, partint d'aquest marc, la formació dels professionals de l'empresa que es proposa té els objectius següents:

a) Ampliar el repertori comunicatiu a partir de les pràctiques comunicatives reals de cada empresa.

b) Aprendre a mobilitzar les estratègies amb flexibilitat. No es tracta d'inventar estratègies noves que no hagin estat assajades prèviament en la interacció. Podrien ser igualment desafortunades. Aquest mètode aconsella dissenyar tàctiques basant-se en les que ja han aparegut en el corpus, $i$ tenint en compte l'èxit que han obtingut en relació amb 
diferents factors: tipus de clients, marcs, recursos lingüístics usats o metes comunicatives perseguides.

c) Conèixer els mètodes d'anàlisi bàsics dels estudis sociodiscursius, ja que permeten reflexionar i prendre consciència del procés comunicatiu.

4. Del CORPus de Dades a L'Elaboració DEL REPERTORI COMUNICATIU DE L'EMPRESA

\subsection{Observació etnogräfica i elaboració del corpus de dades de l'empresa}

El primer pas consisteix a fer una recollida etnogràfica de les pràctiques comunicatives rellevants de l'empresa aplicant la metodologia del participant-observador, àmpliament utilitzada en les investigacions sociodiscursives des de la dècada de 1960, és a dir, que l'investigador combina l'observació de les activitats comunicatives i en recull les impressions en un quadern de camp, les quals enregistra en àudio i/o vídeo. Se'n recomana l'enregistrament encobert per aconseguir la màxima naturalitat de les dades. No obstant això, s'han de prendre les mesures ètiques oportunes sobre la confidencialitat de les dades perquè els informants se sentin segurs. A partir d'aquesta recollida, se seleccionaran les dades que han de ser transcrites per, posteriorment, analitzar-les qualitativament.

\subsection{L'anàlisi}

El segon pas serà l'anàlisi qualitativa dels components principals de les formes típiques de comunicació de l'empresa. Per a aquesta tasca proposem dos models d'anàlisi possibles procedents dels estudis sociodiscursius: el model SPEAKING, proposat per Dell Hymes (1967), i el model de la Gramatica del context de Ron Scollon i Suzanne Wong Scollon (1995).

\subsubsection{El model SPEAKING}

Dell Hymes (1967), pioner de l'etnografia de la comunicació, parteix de les lletres de la paraula SPEAKING per assenyalar els components del procés comunicatiu que cal analitzar:

- Setting. Es refereix tant a la localització espacial, temporal com a l'atmosfera psicosocial. Per exemple, la distribució espacial dels participants en una sala de reunions, en un despatx o en una finestreta d'atenció al client és fonamental per detallar-ne les funcions, les relacions de poder i definir els tipus d'intercanvi.

- Participants. Els diferents participants que intervenen en la interacció i els rols que ocupen.

- Ends. Es refereix tant als objectius de la interacció com als productes que s'obtenen (informar, negociar, persuadir/convèncer, etc.).

- Act sequences. Seqüència d'actes en els quals s'estructura la interacció.

- Key. Es refereix al grau de formalitat/informalitat de la interacció i al to (seriós/lúdic, consensual/conflictiu, íntim/distant).

- Instruments. Els instruments inclouen:

a) Canal: auditiu, visual, audiovisual.

b) Varietats lingüístiques i registres de la interacció.

c) Elements cinèsics i proxèmics.

- Normes. Inclou les normes d'interacció i d'interpretació. Serveixen per qualificar una actuació com a apropiada.

- Gènere. Els gèneres s'entenen des d'un punt de vista sociocultural com a pràctiques discursives a les quals s'associen uns usos lingüísticocomunicatius determinats: compra-venda, reunió de negocis, informació al client, presentació d'un producte, etc.

\subsubsection{El model de la Gramática del context}


Ron Scollon i Suzanne Wong Scollon (1995) proposen l'anàlisi dels components següents:

- Escena. Inclou l'observació del temps, la localització de la trobada i l'ús de l'espai. També s'analitza la funció de l'intercanvi comunicatiu, el tema i el gènere.

- Clau. Es descriu la comunicació (conflictiva, agressiva, distesa, etc.).

- Participants. Es descriuen els rols dels participants en la interacció.

- Forma del missatge. S'atendrà el canal del missatge (oral, escrit, audiovisual, etc).

- Seqüències. Anàlisi de l'estructura interna de l'activitat comunicativa.

- Patrons de coocurrència. Les circumstàncies i patrons esperables en cada tipus d'activitat comunicativa (formalitat, normes de comportament verbal, etc.).

- Claredat i efectivitat. Es valora si la intenció comunicativa es presenta en el missatge de manera ambigua, com també la pertinència de la informació aportada. Un missatge difícil d'entendre tindrà menys probabilitats d'aconseguir les metes per a les quals ha estat elaborat, això és, serà poc efectiu.

\subsection{L'elaboració del repertori d'estratègies de l'empresa}

El resultat de l'anàlisi qualitativa revela informació rellevant sobre la gestió de la comunicació en l'empresa. És també important rendibilitzar recursos d'anàlisis de la pragmàtica i de l'anàlisi de la conversa per detallar les peculiaritats de les seqüències d'actes, instruments, claus, normes d'interacció, etc. L'estudi sociodiscursiu detallat serveix per elaborar el repertori d'estratègies de l'empresa.

Per exemple, en Morales López, Prego Vázquez i Domínguez Seco (2005, 2006), es mostra com l'anàlisi dels recursos comunicatius de les interaccions entre els empleats i els clients d'una empresa d'aigües ${ }^{2}$ permet elaborar el repertori d'estratègies (sintetitzat en el quadre que es reprodueix al final d'aquest apartat). Es va observar com aquests recursos es poden classificar en dos grans tipus que es corresponen amb els dos estils comunicatius bàsics que els empleats utilitzen per resoldre els conflictes: estil de personalització i estil de despersonalització.

En l'estil comunicatiu de personalització, l'empatia i la solidaritat són la base de la interacció. L'empleat aclareix els dubtes dels clients amb casos basats en l'experiència personal o en la de l'interlocutor, i vincula les argumentacions a exemples de la vida quotidiana. Sol usar expressions col loquials, com dites o refranys i recorre al sentit comú per explicar millor el procediment de l'empresa. El client té més marge per intervenir $\mathrm{i}$ introduir $\mathrm{i}$ desenvolupar nous temes.

En l'estil comunicatiu de despersonalització, en canvi, es manté l'entrevista en un plànol institucional $\mathrm{i}$ amb dissimetria. L'escena és formal i distant, i hi prevalen sobretot els papers de representant institucional i client. L'argumentació es fonamenta en dades objectives $i$ en aspectes relacionats amb el procediment empresarial o institucional. S'hi inclou terminologia tècnica. Els empleats utilitzen estructures impersonals per presentar-se com a portaveus de l'empresa i eludir responsabilitats individuals. L'empleat controla la interacció i el client el segueix.

\footnotetext{
2 Es tracta d'una empresa semipública (51 \% del capital públic i $49 \%$ privat) que administra l'aigua, sanejament, recollida i tractament de residus en un municipi de Galícia (ometem el nom de l'empresa i de la ciutat per confidencialitat). Les dades es van obtenir durant l'any 2001, uns mesos després del procés que va emprendre aquest municipi per semiprivatitzar aquests serveis.
} 


\begin{tabular}{|c|c|}
\hline $\begin{array}{l}\text { PERSON ALITZACIÓ } \\
\text { Lèxic col loquial } \\
\text { «...Si som espavilats, doncs deu, vint o trenta, } \\
\text { ens arriben... Però si som una mica així...» }\end{array}$ & $\begin{array}{l}\text { DESPERSON ALITZACIÓ } \\
\text { Lèxic tècnic } \\
\text { «El primer rebut que li correspon facturar a } \\
\text { l'empresa...» }\end{array}$ \\
\hline $\begin{array}{l}\text { Estructures sintàctiques amb el subjecte en primera } \\
\qquad \text { persona del singular o plural } \\
\text { «Jo...» } \\
\text { «Vostè digui-li...» }\end{array}$ & $\begin{array}{l}\text { Construccions impersonals, nominalitzacions o construccions } \\
\text { passives. S'evita la primera persona } \\
\text { «El procediment diu...» }\end{array}$ \\
\hline $\begin{array}{l}\text { Aliances (solidaritat) } i \text { simetria } \\
\text { «Vostè té un nom molt bonic.» } \\
\text { «Més o menys com em surt a mi a casa.» }\end{array}$ & $\begin{array}{l}\text { Més distància personal i dissimetria } \\
\text { «A nom de qui té el contracte de l'aigua, sisplau?” }\end{array}$ \\
\hline $\begin{array}{l}\text { «Ja sap que la gent compra sempre més barat } \\
\text { que els altres.» } \\
\text { «És com triar un mal marit.» }\end{array}$ & $\begin{array}{l}\text { Expressions deòntiques i acumulació d'adverbis modals } \\
\text { «La factura ha de ser per a tot el món...» } \\
\text { «L'empresa d'aigües mai no podrà apujar } \\
\text { absolutament gens els preus.» }\end{array}$ \\
\hline $\begin{array}{l}\text { Exemples de la vida quotidiana } \\
\text { «Si vostè em contracta el dilluns, quan em } \\
\text { paga?" } \\
\text { Exemples personals }\end{array}$ & $\begin{array}{l}\text { Procediment institucional } \\
\text { «El consum es cobra ...” }\end{array}$ \\
\hline «Jo a casa faig $x$ rentadores." & «Una rentadora consumeix $x \mathrm{~m}^{3} . »$ \\
\hline $\begin{array}{l}\text { Discurs referit per a justificar les actuacions de la } \\
\text { companyia } \\
\text { «I no és el mateix anar al portal i agafar la } \\
\text { lectura de quinze pisos que haver d'anar casa } \\
\text { per casa: “A veure, deixi'm passar, que vaig a } \\
\text { mirar el comptador.”.» }\end{array}$ & 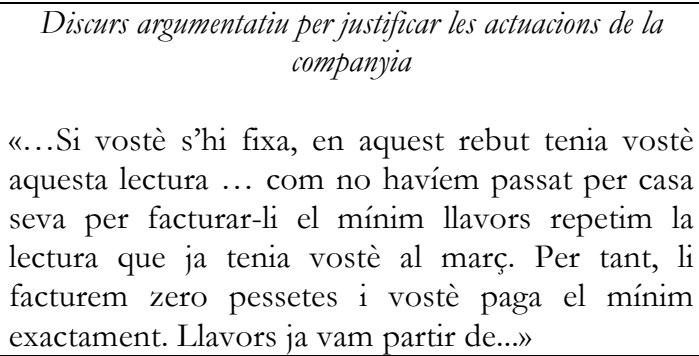 \\
\hline
\end{tabular}

5. DE LA INVESTIGACIÓ A L’APLICACIÓ. L'ELABORACIÓ DE MATERIALS PER A LA FORMACIÓ COMUNICATIVA

L'últim pas consisteix a aplicar els resultats de l'anàlisi a l'elaboració de materials, orientats a forjar la competència metacomunicativa professional dels empleats.

En els apartats següents es proposen tres tipus de recursos: la presentació del repertori d'estratègies, l'informe comunicatiu i la cartera de pràctiques de l'empresa.

\subsection{Presentació del repertori d'estratègies de l'empresa}

El repertori d'estratègies, elaborat des d'un enfocament sociointeraccional, serà un recurs de treball essencial per ampliar els recursos lingüístics dels empleats a partir de pràctiques comunicatives reals. No obstant això, com hem indicat en l'apartat 3, és necessari que els professionals aprenguin a mobilitzar les estratègies amb flexibilitat. Per exemple, l'eficàcia dels estils de personalització i despersonalització dependrà de l'èxit a l'hora de resoldre conflictes. El grau d'adequació dependrà del tipus de client i del problema plantejat en la interacció. Així, l'informe comunicatiu que es proposa en el subapartat següent serà un complement 
essencial per prendre consciència de com funcionen els diferents recursos del repertori en la gestió comunicativa de l'empresa.

\subsection{L'informe comunicatiu de l'empresa}

Un informe comunicatiu que s'elabori en el marc de l'anàlisi del discurs conté: (I) punts febles, és a dir, l'anàlisi dels problemes sorgits per l'ocupació de recursos no adequats al tipus de client, marc de l'intercanvi o meta interaccional (informar, persuadir, etc.); (II) punts forts, de manera que es descriuen situacions similars a les anteriors en les quals el desenllaç va ser afortunat perquè la gestió interaccional i l'adequació dels recursos lingüístics empleats van afavorir l'èxit de la interacció.

Per exemple, l'informe comunicatiu de l'empresa d'aigües a la qual ens referim en els apartats anteriors evidencia que els punts febles de la comunicació externa de l'empresa són: (a) la limitació del repertori comunicatiu dels empleats $i(b)$ la flexibilitat escassa en la gestió dels recursos discursius en el transcurs de la interacció. Així, vam comprovar que la majoria dels empleats usaven només un tipus d'estil comunicatiu (personalització o despersonalització), sense tenir en compte les variables contextuals. La presentació dels punts forts serveix per oferir recursos lingüístics $i$ treballar habilitats discursives noves partint de les interaccions afortunades del corpus. Els exemples del corpus mostren com canviar d'un estil de despersonalització a un de personalització o viceversa pot ser la clau per desblocar un conflicte. Les anàlisis aportades en Morales López, Prego Vázquez i Domínguez Seco (2005, 2006) i Prego Vázquez $(2007 a, 2007 b)$ ho demostren.

\subsection{La cartera de pràctiques de l'empresa}

És un altre recurs de gran utilitat per aprendre a usar i mobilitzar les estratègies més adequades en funció dels factors contextuals. La cartera inclou totes les pràctiques de l'empresa: cartes, fullets dels productes, targetes de presentació, vídeos i transcripcions de reunions, presentacions dels productes, trobades entre els empleats i els clients, interaccions telefòniques, informes $\mathrm{o}$ correus electrònics.

S'aconsella que la selecció la faci un lingüista $o$ un analista del discurs $i$ que inclogui en cada apartat els casos més bons $i$ els més dolents. Els professionals de l'empresa, guiats per l'analista del discurs, han de discutir els materials valorant-ne l'efectivitat comunicativa. Això és, el grup analitza allò que li sembla confús, reflexiona sobre les mancances o el que li sembla excessiu o innecessari en cada cas i proposa estratègies de millora. L'analista del discurs ha d'explicar l'origen dels èxits i els bloquejos comunicatius (Morales López, Prego Vázquez i Domínguez Seco 2006). Aquest tipus de formació comunicativa té com a objectiu oferir recursos per potenciar la reflexió metacomunicativa dels empleats i treballar la competència metacomunicativa professional.

La cartera també és un recurs apropiat per a la gestió de la comunicació intercultural en el món dels negocis. Per exemple, el mètode de Pan, Wong i Scollon (2002) consisteix en l'intercanvi de carteres entre empreses $\mathrm{O}$ equips de treball de països o cultures diferents. El propòsit és que cada grup de treball reflexioni no només sobre la comunicació pròpia sinó també que sigui conscient de les pràctiques de l'altra part. Els autors, seguint els pressupòsits de la sociolingüística interaccional, consideren que els problemes interculturals de comunicació s'originen per no compartir expectatives discursives i patrons d'interacció. En aquest sentit, la tesi és que l'èxit de la comunicació intercultural requereix un enteniment reflexiu del procés comunicatiu. Els autors han mostrat com l'intercanvi de carteres entre empreses situades a Hong Kong, Beijing i Finlàndia va millorar la interacció entre aquests grups de treball (Pan, Wong i Scollon 2002). 


\section{CONSIDERACIONS FINALS}

La formació comunicativa que es proposa en aquest article consisteix a oferir recursos i pautes per reflexionar sobre el procés comunicatiu. Aquesta reflexió metacomunicativa permet als professionals gestionar adequadament els recursos lingüístics i ampliar les possibilitats del repertori d'estratègies.

Aquest sistema de formació consisteix a ensenyar recursos lingüístics basats en l'anàlisi sociodiscursiva del conflicte i de la resolució en pràctiques reals de l'empresa. Es tracta d'un mètode d'investigació-acció que comença en la recollida de dades i finalitza en l'elaboració de materials didàctics. Depenent de la destresa que es posseeixi dels recursos analítics de disciplines com la pragmàtica, la sociolingüística interaccional o l'anàlisi del discurs, l'estudi podrà ser més minuciós i el disseny d'estratègies més adequat.

Un analista del discurs és el professional idoni ja que obtindrà més rendibilitat en l'anàlisi i podrà oferir materials de formació comunicativa més elaborats. Qualsevol empresa que opti per aquest mètode rebrà propostes i solucions concretes per als problemes que tingui. Per aquesta raó, la investigació-acció constitueix una forma eficaç de millorar la comunicació en els contextos professionals.

\section{Bibliografia}

Bargiela-Chiappini, F. i Harris, S. (ed.) (1997). The Languages of Business. An International Perspective. Edimburg: Edinburgh University Press.

Boden, D. i Zimmerman, D. H. (ed.) (1991). Talk and Social Structure. Berkeley: University of California Press.

Drew, P. i Heritage, J. (ed.) (1992). Talk at Work. Interaction in Institutional Settings. Cambridge: Cambridge University Press.

Gumperz, J. J. (1982a). Discourse Strategies. Cambridge: Cambridge University Press.
GumperZ, J. J. (ed.) (1982b). Language and Social Identity. Cambridge: Cambridge University Press.

Gumperz, J. J.; Jupp, T. i Roberts, C. (1979). Crosstalk: A Study of Cross-Cultural Communication. Londres: National Centre for Industrial Language Training in association with the BBC.

Gumperz, J. J. i Hymes, D. (ed.) (1972). Directions in Sociolinguistics: The Ethnography of Communication. Nova York: Holt, Rinehart \& Winston.

GunNarson, B.; Linnel, P. i NordberG, B. (1997). The Construction of Proffessional Discourse. Londres/Nova York: Longman.

Hymes, D. H. (1967). «Models of the interaction of language and social setting». Journal of Social Issues 23, 2, 8-28.

Martín-Rojo, L. i Gómez-Esteban, C. (2002). «Discourse at Work: When Women Take on the Role of Managern, en WODAK, R. i Weiss, G. (ed.). Theory and Interdisciplinarity. Londres: Macmillan/Pagrave, pàg. 241-271.

Morales López, E.; Prego Vázquez, G. i Domínguez Seco, L. (2005). «Interview between employees and customers during a company restructuring process». Discourse and Society, 16(2), pàg. 225-268.

Morales López, E.; Prego Vázquez, G. i Domínguez SECO, L. (2006). El conflicto comunicativo en la empresa desde el Análisis del Discurso. A Coruña: Universidade da Coruña.

Pan, Y.; Wong, S. i Scollon, R (2002). Professional Communication in International Settings. Oxford: Blackwell.

Prego VÁzQuez, G. (2007a). «Frame Conflict and Social Inequality in Workplace: Professional and Local Discourse Struggle in Employees/Customers Interactions». Discourse and Society, 18, 3, pàg. 295-336.

Prego VÁzQuez, G. (2007b). «Los recursos interaccionales del poder como mecanismos de negociación de identidades profesionales». RILI, 1, 9, pàg. 111-124. 
SARAngi, S. i Roberts, C. (ed.) (1999). Talk, Work and Institutional Order. Discourse in Medial, Mediation and Management Settings. Berlín: Gruyter.

SCOllon, R. i Wong Scollon, S. (1995). Intercultural Communication. Oxford: Blackwell.

Verschueren, J. (1999). Para entender la pragmática. Madrid: Gredos.

WODAK, R. (1996). Disorders of Discourse. Londres/Nova York: Longman. 